\title{
A COMPREENSÃO DA OMC SOBRE A CERTIFICAÇÃO 'DOLPHIN SAFE' NA PESCA DO ATUM: O CASO US TUNA II
}

\author{
Joana Stelzer ${ }^{1}$ \\ Universidade Federal de Santa Catarina (UFSC) \\ Everton das Neves Gonçalves ${ }^{2}$ \\ Universidade Federal de Santa Catarina (UFSC) \\ Keite Wieira $^{3}$ \\ Escola Superior de Criciúma (ESUCRI)
}

\section{RESUMO}

O presente estudo tem como objetivo a análise do caso US Tuna II, julgado pelo Sistema de Solução de Controvérsias da OMC para identificar o papel da certificação (Dolphin safe) imposta pelos Estados Unidos na pesca de atum, visando à proteção dos golfinhos. Essa apreciação desenvolveu-se à luz do Acordo de Barreiras Técnicas ao Comércio da OMC, bem como sob a ótica da definição e da conceituação de regulamento técnico. Para que se pudesse atingir a conclusão desejada, fez-se necessária a compreensão do caso, do acordo citado, incluindo os princípios do Tratamento Nacional, da Nação Mais Favorecida, da criação de obstáculos desnecessários ao comércio internacional e da harmonização; do conceito de regulamento técnico e, por fim, das decisões do painel e do órgão de apelação. Com base nessas informações, analisou-se a decisão final do caso sob a diretriz da adequação às normas da $\mathrm{OMC}$ sobre barreiras e sob a ótica das condições justas de concorrência no comércio internacional. Quanto à metodologia,

1 Pós-doutora em Direito pela Universidade de São Paulo (USP). Doutora e Mestre em Direito, na área de Relações Internacionais, pela Universidade Federal de Santa Catarina (UFSC). Professora Associada I na UFSC. Professora credenciada no Programa de Pós-Graduação em Direito da Universidade Federal de Santa Catarina (PPGD/CCJ/UFSC) para Mestrado e Doutorado. / ORCID: http://orcid.org/0000-0002-9503-4080 / e-mail: contatojoana@yahoo.com.br

2 Doutor em Direito, na área de Direito Econômico, pela Universidade Federal de Minas Gerais (UFMG). Doctor en Derecho, área de Derecho Internacional Económico, por la Universidad de Buenos Aires (UBA). Mestre em Direito pela UFSC. Professor titular na UFSC. Professor credenciado no Programa de Pós-Graduação em Direito da Universidade Federal de Santa Catarina (PPGD/ CCJ/UFSC) para Mestrado e Doutorado. ORCID: http://orcid.org/0000-0002-5116-9362 / e-mail: evertong@veorial.net

3 Doutoranda em Direito, na área de Direito Internacional, Econômico e Comércio Sustentável. Mestre em Direito (UFSC), na área de Relações Internacionais, pela UFSC. Especialista em Direito da Aduana e do Comércio Exterior Brasileiro pela Universidade do Vale do Itajaí (UNIVALI). Professora no Curso de Direito da Escola Superior de Criciúma (ESUCRI). ORCID: http://orcid.org/0000-00025319-5548 / e-mail keitewieira@gmail.com 
trata-se de uma pesquisa pura, qualitativa e descritiva. O método de abordagem foi o indutivo crítico, de interpretação lógico-gramatical e procedimento técnicos documentais.

Palavras-chave: Acordo de Barreiras Técnicas ao Comércio; certificação de proteção animal; Dolphin safe; US TUNA II.

\section{WTO UNDERSTANDING ON CERTIFICATION 'DOLPHIN SAFE' IN TUNA FISHING: THE US TUNA II CASE}

\section{ABSTRACT}

The present study aims to analyze the US Tuna II case adjudicated by the WTO Dispute Settlement System to identify the role of the United States' dolphin safe certification for tuna fishing. This assessment was developed in the light of the WTO's Technical Barriers to Trade Agreement, as well as from the point of view of the definition and conceptualization of technical regulations. In order to achieve the desired conclusion, it was necessary to understand the case, the above-mentioned agreement, including the National Treatment and the Most Favored Nation principles, the creation of unnecessary obstacles to international trade and harmonization; the concept of a technical regulation and, lastly, the decisions of the Panel and the Appellate Body. Based on these information, the final decision of the case was analyzed under the guideline of compliance with the WTO rules on barriers and from the point of view of fair conditions of competition in international trade. As for the methodology, it is pure, qualitative and descriptive research. The method of approach was the critical inductive, logical-grammatical interpretation and documentary technical procedure.

Key-words: Agreement on Technical Barriers to Trade; certification of animal protection; Dolphin safe; US TUNA II. 


\section{INTRODUÇÃO}

A compreensão e o papel da certificação (Dolphin safe) imposta pelos Estados Unidos na pesca de atum, visando à proteção dos golfinhos e tendo por base as normas de barreiras técnicas estabelecidas pela Organização Mundial de Comércio (OMC), retorna ao centro das discussões, em virtude de suas inquietantes motivações jurídicas.

Do ponto de vista fático, cumpre esclarecer que, por razões ainda pouco conhecidas, cardumes de atum nadam frequentemente debaixo de grandes grupos de golfinho, e desde 1959 os pescadores de atum utilizam essa associação para capturar esses peixes. Entretanto, muitos consumidores passaram a exigir da atividade pesqueira o respeito a padrões éticos de direito animal, pois a pesca do atum implicava trazer a bordo golfinhos extenuados da perseguição. Mesmo devolvidos ao mar, os golfinhos geralmente morriam depois da prática predatória. Tal fato conduziu à criação da etiqueta Dolphin Safe, muito utilizada nos Estados Unidos, exigindo que o lançamento das redes não fosse mais feito de forma deliberada sobre os golfinhos.

Em junho de 1994, duas atitudes foram tomadas: a adoção da etiqueta por parte da frota atuneira estadunidense e a proibição da importação de atum capturado em países que não reproduzissem tal prática. As discussões, contudo, não se encerraram por tal circunstância. Com efeito, países que se viram obrigados a seguir o marco ambiental protetivo (em detrimento de outros que não necessitavam seguir a regra) invocaram inconsistência perante a Organização Mundial do Comércio (OMC), a exemplo do México.

Tendo em vista tais considerações, o estudo foi problematizado no sentido de apreciar a decisão do órgão de solução de controvérsias da OMC não apenas sob a ótica da adequação às normas sobre barreiras técnicas, mas também sob condições justas de concorrência no mercado internacional. Assim, descreveu-se a posição da OMC diante da celeuma: a regulamentação estadunidense que condiciona o uso da certificação de proteção aos golfinhos enquadra-se no conceito de um regulamento técnico? A hipótese diz respeito à restrição trazida pela norma estadunidense que ofereceria um tratamento diferenciado e desfavorável ao México - e que levou o caso até a $\mathrm{OMC}$-, pois, ao restringir o uso do selo com normas desproporcionais e discriminatórias (pesca na área ETP), estar-se-ia restringindo o acesso do atum mexicano ao mercado estadunidense. Com 
efeito, já é de conhecimento da comunidade de comércio internacional que o atum que não se utiliza do selo de proteção aos golfinhos sofre grande rejeição por parte do consumidor estadunidense.

Para elucidação da hipótese, o objetivo geral consistiu em descrever as razões de confrontamento no Processo Tuna II, por parte tanto dos Estados Unidos quanto do México. Os objetivos específicos cingiram-se em: descrever os dilemas que envolviam o processo e que estavam centrados na eficiência protetiva da certificação Dolphin Safe; discutir a finalidade protecionista das barreiras técnicas invocadas; e evidenciar a decisão proferida pela OMC, que passou pelo Relato das decisões do Grupo Especial (Panel) e do grupo de apelação (Appellate Body) do Sistema de Solução de Controvérsias da OMC.

Entre as teorias que se apresentam para trazer o almejado detalhamento, enveredou-se pela própria argumentação da OMC, com destaque para a análise hermenêutica. Assim, uma vez estabelecido o marco teórico com base nos autores Silvia M. de Oliveira (2005) e Alan O. Sykes (2017), a análise voltou-se ao conceito de regulamento técnico, bem como ao Acordo de Barreiras Técnicas da OMC, incluindo os princípios do Tratamento Nacional, da Nação Mais Favorecida, da Criação de Obstáculos Desnecessários ao Comércio Internacional e da Harmonização.

No que tange à metodologia, quanto à natureza, trata-se de pesquisa pura, pois houve grande interesse em decifrar a compreensão do que são barreiras técnicas. Quanto à abordagem do problema, trata-se de estudo qualitativo amparado pela interpretação das normas por parte do Sistema de Solução de Controvérsias da OMC. Quanto aos fins, foi descritiva, no afã de apontar os principais pontos que estruturaram o acórdão emanado. O método de abordagem foi o indutivo crítico, sem desconhecer sua fragilidade, já que não se podem assegurar futuras decisões da OMC com a lógica impregnada no Tuna II. Ainda assim, diante da complexidade do processo, o referido método foi útil, na medida em que permitiu o deslinde das ideias-chaves que nortearam o acórdão. Quanto ao método de interpretação, foi lógico-gramatical, e quanto aos procedimentos técnicos, foi majoritariamente documental. 


\section{O CASO US TUNA II MEDIANTE AS CERTIFICAÇÕES DOLPHIN SAFE E SETTING ON DOLPHINS}

Talvez por um critério geográfico, tratando-se de países vizinhos com maior facilidade logística em importação e exportação, a disputa entre os Estados Unidos e o México sobre a comercialização de atum e a proteção dos golfinhos, pescados na área leste do Pacífico - Eastern Tropical Pacific $(E T P)$, seja antiga. Em outubro de 2008, após a promulgação da legislação interna estadunidense U.S. Dolphin Protection Consumer Information Act regulamentando as condições sob as quais o atum pescado na zona leste do pacífico poderia ser comercializado aos Estados Unidos, utilizando-se do selo de proteção aos golfinhos (Dolphin Safe Label), sob as regras do Sistema de Solução de Controvérsias da Organização Mundial de Comércio (OMC), o México acionou os Estados Unidos, na forma de consulta.

Sendo infrutífera a tentativa obrigatória de acordo, em março de 2009 estabeleceu-se um grupo especial para julgar o caso enumerado 381, analisando as inconsistências apontadas pelo México. Outros países, entre eles o Brasil, integraram a disputa na qualidade de terceiro interessados, garantindo sua participação por meio de manifestações ao longo do processo.

Quanto à essência do caso, cumpre analisar as supostas medidas inconsistentes que os Estados Unidos estariam tomando em detrimento do México. A legislação estadunidense em questão tornou-se norma no ordenamento jurídico. com o objetivo de padronizar e regulamentar as condições de uso do selo de proteção aos golfinhos - Dolphin Safe. Para tanto, a norma atacou, entre outras questões, a técnica de pesca conhecida como Setting on Dolphins.

Dentro da área leste do pacífico existe uma associação natural entre os golfinhos e o atum. Em razão da habilidade do atum em nadar tão rápido quanto os golfinhos, cogita-se ser este o motivo de as duas espécies se tornarem companheiras de nado. Fruto dessa associação, criou-se uma técnica de pesca (Setting on Dolphins) na qual, ao avistar os golfinhos na superfície, os pescadores lançam as redes sob eles, buscando capturar o atum que costuma nadar rente à barriga dos golfinhos. Essa técnica de pesca acaba resultando no alto índice de mortalidade dos golfinhos, já que, quando da separação dos peixes, muitos daqueles acabam sendo mortos ou gravemente feridos. Ainda, os filhotes que dependem de suas mães, quando delas separados, acabam morrendo de fome ou tornam-se presas fáceis aos predadores. 
Diante de tal situação, a legislação estadunidense previu que os pescadores usuários de tal técnica estariam proibidos de fazer uso do selo de proteção de golfinhos nas embalagens dos produtos destinados à importação no país americano. No mais, independentemente da técnica utilizada, para que o atum pescado no leste do pacífico (ETP) recebesse o dito selo, seria necessário que o capitão do navio e outro observador certificassem que nenhum golfinho havia sido morto ou gravemente ferido durante o processo de pesca daquele atum. Importante desde já ressaltar que a lei não previu a aplicação de tal critério para os pescados de nenhuma outra região, senão o ETP (SYKES, 2017).

Importante, ainda, destacar que, apesar de os Estados Unidos já terem abandonado a técnica Setting on Dolphins, o método ainda era utilizado pelo México, que era o operador de pesca mais frequente naquela região (SYKES, 2017). Como a maior parte do atum vendido e exportado pelo México não se qualificava para o selo, o país desfavorecido pela medida socorreu-se da OMC por meio da instauração do caso já narrado. $\mathrm{O}$ protocolo mexicano deixou claro que o país estava em conformidade com o Acordo Internacional da Conservação dos Golfinhos (Agreement on the International Dolphin Conservation Program - AIDCP), que prevê medidas de redução da mortalidade dos golfinhos sem, contudo, proibir a técnica Setting on Dolphins (SYKES, 2017). Destaca-se que o acordo, inclusive, dispõe de regras para a utilização do selo de proteção aos golfinhos (IATTC, 2005) e que essas normativas diferem daquelas criadas pela legislação estadunidense, por se tratar de selos diferentes, porém, com o mesmo objetivo: garantir a segurança dos golfinhos.

Ainda, os mexicanos foram pontuais ao afirmar que a técnica condenada pela legislação estadunidense não era utilizada apenas no ETP, mas em outras regiões oceânicas do mundo, onde também seria comum a associação do atum com os golfinhos. As principais inconsistências apontadas pelo México, referentes à medida de certificação, eram relativas aos artigos 2.1, 2.2 e 2.4 do Acordo de Barreiras Técnicas ao Comércio Internacional (Agreement on Technical Barriers to Trade - TBT) e dispositivos correspondentes do GATT.

A defesa estadunidense caminhou no sentido de que sua legislação não visava impor barreiras técnicas à importação, e sim regulamentar o uso do selo de proteção dos golfinhos. Nada impedia que o México, caso continuasse a pescar no ETP, com a técnica não aceita, exportasse seu produto para os Estados Unidos sem o respectivo selo, e por tal razão não haveria que se falar em restrições à importação. 
Ainda, é importante mencionar que essa não foi a primeira oportunidade em que o país americano foi réu em procedimento movido pelo país mexicano. No ano de 1990, o México solicitou uma consulta com os Estados Unidos alegando que suas medidas em prol do atum estavam restringindo e proibindo a importação do atum mexicano. Tal pedido resultou em um relatório do então grupo especial do sistema GATT (WTO, 2019d), conhecido como US TUNA I.

Na época, a Lei de Proteção aos Mamíferos, levada à vigência pela Marinha Americana, proibiu, por meio de embargo, salvo ressalvas, a importação do atum pescado na zona do ETP, por causar, supostamente, dano aos mamíferos daquela região. A defesa do país americano, no procedimento à luz do sistema de solução de controvérsias do GATT 47, afirmou tratar-se de uma medida excepcional que tem enquadramento no artigo XX do GATT, alíneas b e g (medidas necessárias à proteção dos animais e relativas à conservação dos recursos naturais esgotáveis). No entendimento de Orlando Celso da Silva Neto (2006), a medida restritiva autorizada pelo artigo XX do GATT, ainda que implicasse obstáculos ao livre comércio, era legítima quando visava assegurar os objetivos listados no rol do dispositivo, desde que não fosse aplicada de forma injustificada, discriminatória e excessivamente restritiva.

Nesse sentido, o Grupo Especial entendeu que, de fato, estava com razão o México, já que os Estados Unidos estavam agindo em desconformidade com o artigo XI do GATT 47, que vedava restrições e/ ou proibições quantitativas na importação. Tal foi o entendimento pois se destacou não haverem provas suficientes para demonstrar que a Lei da Marinha Americana buscava a proteção alegada em relação ao meio ambiente e aos mamíferos, sem restringir o comércio internacional de forma discriminatória.

Ocorre que, ainda que o México tenha obtido êxito no litígio, perante o relatório do órgão julgador do GATT, esse relatório não foi adotado pelos países membros, deixando de produzir efeitos jurídicos. Como os países envolvidos estavam travando negociações paralelas no acordo North American Free Trade Agreement (NAFTA), a questão deixou de ter destaque no sistema multilateral de comércio.

Nessa segunda oportunidade, vale dizer, no caso US TUNA II (supra explanado), já sob a jurisdição do Sistema de Solução de Controvérsias da OMC, novamente os Estados Unidos editam normativa interna que passou a restringir a importação mexicana do atum, porém, dessa vez, a lei estadunidense pautou-se na certificação em prol dos golfinhos. 


\section{SELO DOLPHIN SAFE: ENTRE A PROTEÇÃO ANIMAL E A BARREIRA TÉCNICA AO COMÉRCIO INTERNACIONAL}

Uma vez que a celeuma se formou com base no questionamento acerca do enquadramento da medida estadunidense enquanto barreira técnica, cumpre discutir a finalidade protecionista das ditas barreiras técnicas:

A maioria dos standards e regulamentos técnicos são adotados com o fim de proteger
a saúde ou a segurança humana. [...] Também a vida ou a saúde animal e vegetal
podem ser objeto de proteção por uma barreira técnica, incluindo regulamentos
voltados a assegurar que as espécies animais e vegetais não sejam extintas [...] (OLIVEIRA, 2005, p. 292).

No caso em análise, apesar de a barreira imposta pelos Estados Unidos (requisitos para a certificação Dolphin Safe) visar à proteção de uma espécie de animais (os golfinhos), o México entendeu que tal regulamentação estaria acobertando uma verdadeira medida protecionista de sua indústria nacional, até porque se sabe que "as barreiras técnicas podem ser facilmente manipuladas para encobrir medidas protecionistas" (OLIVEIRA, 2005, p. 278).

A motivação do México para promover o pedido de consulta e, posteriormente, o pedido de instauração do painel era "[...] o uso de standards e regulamentos técnicos com o propósito de restringir o comércio e discriminar fornecedores estrangeiros" (OLIVEIRA, 2005, p. 278), por meio da certificação, pois “[...] o próprio processo de certificação poderia ser utilizado com propósitos protecionistas [...]" (OLIVEIRA, 2005, p. 280), até porque as restrições foram impostas pelo próprio Estado que pesca e vende atum, concorrendo com o atum mexicano importado em seu mercado nacional. Como já mencionado, os principais artigos do Acordo de Barreiras Técnicas que foram apontados no caso são:

2.1: Os Membros assegurarão, a respeito de regulamentos técnicos, que os produtos importados do território de qualquer Membro recebam tratamento não menos favorável que aquele concedido aos produtos similares de origem nacional e a produtos similares originários de qualquer outro país (WTO, 2019a).

Esse artigo traz a regra da Nação Mais Favorecida e do Tratamento Nacional, além de estabelecer que nenhum Estado membro deve receber tratamento menos favorecido em termos de barreiras técnicas. Assim, determina que o mesmo tratamento nacional deve ser estendido aos produtos importados de outros estados membros. Ambas as regras são 


\section{descritas da seguinte forma:}

O parágrafo $1^{\circ}$ do artigo $2^{\circ}$ estabelece a respeito dos regulamentos técnicos que os produtos importados do território de qualquer membro devem receber tratamento não menos favorável que aqueles concedidos aos produtos similares de origem nacional e a produtos similares originários de qualquer outro pais. Essas obrigações também se aplicam aos procedimentos de avaliação de conformidade, os quais devem ser aplicados a produtos importados de outros membros da $\mathrm{OMC}$ de maneira não menos favorável do que aquela acordada a produtos similares de origem nacional e a produtos similares originados de qualquer outro pais (OLIVEIRA, 2005, p. 294).

Já o artigo 2.2, ainda do Acordo de Barreiras Técnicas, também apontado pelo México como violado, perante a medida protecionista estadunidense, prevê:

Os Membros assegurarão que os regulamentos técnicos não sejam elaborados, adotados ou aplicados com a finalidade ou o efeito de criar obstáculos técnicos ao comércio internacional. Para este fim, os regulamentos técnicos não serão mais restritivos ao comércio do que o necessário para realizar um objetivo legítimo, tendo em conta os riscos que a não realização criaria. Tais objetivos legítimos são, inter alia: imperativos de segurança nacional; a prevenção de práticas enganosas; a proteção da saúde ou segurança humana, da saúde ou vida animal ou vegetal, ou do meio ambiente. Ao avaliar tais riscos, os elementos pertinentes a serem levados em consideração são, inter alia: a informação técnica e científica disponível, a tecnologia de processamento conexa ou os usos finais a que se destinam os produtos (WTO, 2019a).

$\mathrm{O}$ artigo 2.2, por seu turno, traduz a regra da não imposição de obstáculos desnecessários ao comércio. Tratando-se de um acordo de barreiras técnicas, é essencial estabelecer que, mesmo sendo um tema regulamentado, ou seja, legítimo de imposição, não se pode aceitar que sejam estipulados obstáculos desnecessários ao bom desenvolvimento do comércio. Assim, não pode um obstáculo ser mais restritivo ao comércio do que o necessário para alcançar o objetivo de proteção almejado.

Como objetivos legítimos são reconhecidos no parágrafo $2^{\circ}$ do artigo $2^{\circ}$, inter alia, imperativos de segurança nacional, a prevenção de práticas enganosas, a proteção da saúde ou segurança humana, da saúde ou vida animal ou vegetal, ou do meio ambiente. [...] um regulamento técnico e um obstáculo desnecessário ao comercio quando: (i) é mais restritivo do que o necessário para atingir um dado objetivo, ou (ii) o objetivo visado não é legitimo; e um regulamento é mais restritivo do que o necessário quando o objetivo perseguido possa ser atingido por meio de medidas alternativas que tenham efeitos menos restritivos ao comércio, levando-se em conta os riscos que a não realização do objetivo criaria (OLIVEIRA, 2005, p. 295). 


\section{Cita-se, ainda, o artigo 2.4 do Acordo de Barreiras Técnicas:}

Quando forem necessários regulamentos técnicos e existam normas internacionais pertinentes ou sua formulação definitiva for iminente, os Membros utilizarão estas normas, ou seus elementos pertinentes, como base de seus regulamentos técnicos, exceto quando das normas internacionais ou seus elementos pertinentes sejam um meio inadequado ou ineficaz para a realização dos objetivos legítimos perseguidos, por exemplo, devido a fatores geográficos ou climáticos fundamentais ou problemas tecnológicos fundamentais (WTO, 2019a).

O referido artigo remete à regra da harmonização.

$\mathrm{O}$ acordo estimula, em conformidade com o parágrafo $4^{\circ}$ do artigo $2^{\circ}$, o uso dos standards internacionais existentes para a elaboração dos regulamentos nacionais, ou parte deles, exceto quando tais standards internacionais ou seus elementos sejam um meio inadequado ou ineficaz para a realização dos objetivos legítimos perseguidos, por exemplo, devido a fatores geográficos ou climáticos fundamentais ou problemas tecnológicos fundamentais. Neste particular, destaca-se o uso da expressão por exemplo, o que não limita os fatores capazes de atribuir ineficiência e inadequação aos standards para a realização dos objetivos perseguidos (OLIVEIRA, 2005, p. 295).

Tendo-se analisado as possíveis inconsistências da medida estadunidense apontadas pelo México, parte-se para a análise da linha de defesa dos Estados Unidos. Para tanto, faz-se imperioso analisar quais são os requisitos de um regulamento técnico. Em outras palavras, é necessário verificar se a regulamentação estadunidense que condiciona o uso da certificação de proteção aos golfinhos se enquadra no conceito de regulamento técnico, uma vez que, não havendo compatibilidade entre os conceitos, não há que se falar em inconsistência na medida estadunidense ou de desrespeito às normas da $\mathrm{OMC}$ apontadas pelo país mexicano. Assim sendo, cumpre observar o conceito de regulamento técnico exarado no item 1 do anexo 1 do TBT:

1 Regulamento Técnico: Documento que enuncia as características de um produto ou os processos e métodos de produção a ele relacionados, incluídas as disposições administrativas aplicáveis, cujo cumprimento é obrigatório. Poderá também tratar parcial ou exclusivamente de terminologia, símbolos e requisitos de embalagem, marcação ou rotulagem aplicáveis a um produto, processo ou método de produção (WTO, 2019a).

Da leitura, tem-se que um regulamento técnico é destinado a produto específico que dispõe sobre os métodos de processamento e produção. Além do que, tratando-se de regulamento técnico, sua aplicação é compulsória. 
Sob essa ótica, parte-se para a análise de todos esses requisitos e aplicações legais sob a interpretação do grupo especial e do grupo de apelação responsáveis pelo caso México $\times$ Estados Unidos. Importante, portanto, lembrar que em nenhum momento o país americano colocou restrições à importação de atum pescado no ETP, e sim ao uso do selo Dolphin Safe.

\section{SEGURANÇA AO GOLFINHO OU REGULAMENTO TÉCNICO: A DECISÃO DO SISTEMA DE SOLUCÃO DE CONTROVÉRSIAS DA OMC}

A decisão proferida pela $\mathrm{OMC}$ passou pelo Relato das decisões do Grupo Especial (Panel) e do grupo de apelação (Appellate Body) do Sistema de Solução de Controvérsias da OMC, analisando a aplicação dos dispositivos legais da organização.

O primeiro ponto analisado pelo Grupo Especial foi referente ao enquadramento da norma estadunidense como Regulamento Técnico. Para verificar se a medida estabelecida pelos Estados Unidos era um regulamento técnico, o que apresenta caráter obrigatório, e não uma norma técnica, de caráter facultativo/voluntário, pautou-se no Anexo 1, do Acordo de Barreiras Técnicas (Acordo ABTC). O Relatório do Grupo Especial estabeleceu:

7.54 Portanto, consideramos agora se as medidas dos Estados Unidos impugnadas pelo México constituem um regulamento técnico na acepção do Anexo 1.1 do Acordo ABTC, com base nesses três elementos, conforme articulado pelo Órgão de Apelação.

7.55 Consequentemente, consideraremos as seguintes questões por sua vez:

(a) Se as disposições de rotulagem dolphin-safe dos Estados Unidos se aplicam a um grupo identificável de produtos;

(b) Se eles estabelecem uma ou mais características desses produtos;

(c) Se o cumprimento deles é obrigatório na acepção do Anexo 1 (WTO, 2019b, p. 135).

De acordo com a análise do Grupo Especial, todas as características de um regulamento técnico estavam presentes na medida estadunidense: (a) produto identificável: o atum; (b) estabelecimento de uma ou mais características do produto: a determinação de requisitos para o uso do selo, aplicando-se a um método de processo, que seria a forma de pesca; e (c) obrigatoriedade: de fato, a medida estadunidense relativa ao selo Dolphin Safe era compulsória. Para que se pudesse fazer uso do selo, era necessário cumprir as determinações legais impostas pela medida doméstica. 
Dos requisitos citados, o último demandou maior análise: a obrigatoriedade da medida. Isso porque, como apontou a defesa dos Estados Unidos, o país permite a comercialização do atum sem o selo em seu mercado interno, ou seja, não há qualquer obstáculo que afronte as regras da OMC para que o México exporte atum para os Estados Unidos. O que o país americano visou disciplinar foi meramente o uso do selo de proteção aos golfinhos, nos produtos cuja importação é permitida sem qualquer óbice. Para resolver a questão, o Grupo Especial, primeiro, observou o termo "obrigatório" à luz da legislação.

Primeiro observamos que as definições de dicionário do termo "obrigatório" incluem "vinculante", bem como "compulsório, obrigatório, não discricionário", ou "exigido por lei ou mandato obrigatório". Isso sugere que a noção de "obrigatório" pode abranger o caráter juridicamente vinculativo e executável do instrumento, e também pode se relacionar com seu conteúdo, prescrevendo/impondo um determinado comportamento. Observamos também que o Guia ISO/IEC 2 estabelece que a expressão "requisito obrigatório" deve ser usada para significar apenas "um requisito obrigatório por lei ou regulamento" (WTO, 2019b, p. 144).

Sob essa ótica, considerou-se obrigatório o ato de regulamentação legal com força vinculante e compulsória:

Em suma, consideramos que o cumprimento das características do produto ou dos seus métodos ou processos de produção relacionados é "obrigatório" na acepção do Anexo 1.1, se o documento em que estejam contidos tenha o efeito de regulamentar de forma legalmente vinculativa ou compulsória as características em questão, e se prescrever ou impor de forma vinculativa ou compulsiva que determinado produto deva ou não possuir certas características, terminologia, símbolos, embalagens, marcação ou rótulos ou que deve ou não deve ser produzido usando certos processos e métodos de produção (WTO, 2019b, p. 146).

Tendo como clara a definição supra, ou seja, a obrigatoriedade da medida, evoluiu-se para a seguinte análise: independentemente da livre comercialização do atum sem o selo, é necessário compreender se as características estabelecidas para a obtenção do selo em si eram obrigatórias e proibitivas.

Isso porque, para o México, por mais que fosse possível a importação sem o selo, não se pode aceitar que um país membro da OMC tenha uma legislação que estabeleça qualquer característica obrigatória para seus produtos, ainda que seja para a utilização de um selo. Diante de tal argumentação, o Grupo Especial, em seu relatório, decidiu: 
Na presente disputa, o México não alega que as disposições norte-americanas de golfinhos exigem o uso do rótulo de golfinhos. Na verdade, é indiscutível que as medidas em questão não impõem um requisito positivo para rotular os produtos de atum a serem vendidos no mercado dos Estados Unidos como dolphin-safe. Nem as disposições estatutárias e regulamentares nem a decisão judicial impugnada pelo México contêm uma linguagem que impõe o uso do rótulo dolphin-safe para produtos de atum como condição para esses produtos serem comercializados nos Estados Unidos.

O México argumenta, no entanto, que essas medidas exigem negativamente que "os produtos de atum oferecidos para venda nos Estados Unidos não devem possuir certas características", a menos que certas condições sejam atendidas. Especificamente, o México alega que as medidas em questão envolvem a proibição do uso de um rótulo dolphin safe sobre produtos de atum mexicanos comercializados nos Estados Unidos. Na opinião do México, esta proibição pode ser expressa como um requisito de que os produtos do atum oferecidos para venda nos Estados Unidos não devem possuir certas características (por exemplo, marcas distintivas - o rótulo dolphin-safe ou qualquer outra marca ou marca análoga) A menos que os requisitos prescritos sejam cumpridos" (WTO, 2019b, p. 148).

Sob esse norte, a decisão do painel pautou-se no fato de que as medidas são realmente vinculantes. Além de serem emanadas pelo Governo, quem produz todos os atos vinculantes impõe penalidade pelo não cumprimento, já que o não enquadramento nas características impostas pela norma estadunidense implicaria a proibição do uso do selo. No mais, a medida estadunidense não regula apenas o uso do selo de proteção aos golfinhos, como também restringe o uso dos termos "boto" ou "mamífero marinho" e outros relacionados aos golfinhos nas embalagens do atum, caso as condições vinculantes na lei criada por eles não fossem cumpridas.

Em outras palavras, a medida proibia que o México recorresse a qualquer outra legislação, já que existiam outras como o acordo supracitado, nas quais se adequassem, para transferir ao consumidor a informação que colaboravam com a proteção dos golfinhos, conforme segue trecho do relatório do Grupo Especial.

7.142 Em primeiro lugar, as medidas em questão são juridicamente vinculativas e vinculativas de acordo com a legislação dos Estados Unidos (elas são emitidas pelo governo e incluem sanções legais). Esse é um componente importante do caráter "obrigatório" das medidas. Isso, no entanto, não pode necessariamente distinguilos de qualquer padrão que seja protegido contra uso abusivo ou enganador de acordo com a lei geral, como a proteção de marca registrada ou leis contra práticas enganosas. 
7.143 Além disso, no entanto, as medidas em questão prescrevem certos requisitos que devem ser cumpridos para fazer qualquer reclamação relativa à forma como o atum contido no produto foi capturado, em relação aos golfinhos. As medidas regulam não apenas o uso do rótulo específico em questão, mas mais amplamente o uso de uma gama de termos para a oferta de venda de produtos de atum, além da própria denominação específica dolphin safe. As medidas em questão proíbem assim o uso de outros termos como "mamífero marinho" ou qualquer declaração relativa a golfinhos, ou animais marinhos, sendo informação enganosa ou não, se as condições estabelecidas no regulamento não forem cumpridas (WTO, 2019b, p. 152).

Então, diante dessa descrição, as medidas estadunidenses deixavam claro que regulavam não apenas o uso do rótulo específico, mas toda uma série de termos para venda de produtos de atum (além, naturalmente, da própria denominação Dolphin Safe). De acordo com os Estados Unidos, haveria um status e um tipo jurídico a ser obedecido.

7.144 Além disso, as medidas incorporam o cumprimento de um padrão específico como o meio exclusivo para afirmar um status dolphin safe para produtos de atum. As medidas não deixam qualquer critério para recorrer a qualquer outro padrão para informar os consumidores sobre a segurança dos golfinhos, do que satisfazer os requisitos específicos da medida. Efetivamente, o padrão dolphin safe refletido nas medidas em questão é, em virtude dessas medidas, o único padrão disponível para resolver o problema. Através do acesso ao selo, as medidas efetivamente regulam o status dolphin safe dos produtos de atum de forma vinculativa e exclusiva e prescrevem, de forma positiva e negativa, os requisitos para reivindicações do selo. Isso distingue esta situação de uma em que, por exemplo, várias normas concorrentes podem coexistir em relação à mesma questão, com reivindicações diferentes, mas relacionadas, cada uma das quais pode ser protegida por direito próprio (WTO, 2019b, p. 152).

Com efeito, diante dessa descrição, as medidas estadunidenses deixavam claro que não havia possibilidade de outro critério para informar os consumidores sobre a segurança dos golfinhos. Unicamente por intermédio do padrão Dolphin Safe dos Estados Unidos os produtos de atum eram comercializados de forma vinculativa e exclusiva.

7.145 A luz de tudo o que precede, consideramos que as medidas em questão estabelecem requisitos de rotulagem, cujo cumprimento é obrigatório. À luz da nossa conclusão de que as medidas em questão estabelecem os requisitos de rotulagem obrigatória, não consideramos necessário considerar o argumento do México além de serem também obrigatórios de fato (WTO, 2019b, p. 152).

Em decorrência dessa análise, o Grupo Especial de julgamento do Sistema de Soluções de Controvérsias da OMC entendeu que a medida 
imposta pelos Estados Unidos era de fato obrigatória, configurando-se como regulamento técnico. Tendo por base que a norma estadunidense se caracterizava como regulamento técnico, coube ao Grupo Especial verificar se esse regulamento técnico desrespeitava as regras estabelecidas no Acordo de Barreiras Técnicas (com remissão a artigos do GATT).

Primeiro, para configurar as supostas irregularidades em face do Princípio da Nação Mais Favorecida e o Princípio do Tratamento Nacional, coube analisar se o atum comercializado pelo México era produto similar aos demais atuns exportados aos Estados Unidos e vendidos pelo próprio país. Para que um produto seja similar, de acordo com a visão do Grupo Especial, seria necessário que os produtos em análise (atum mexicano, atum americano e atum de outros países membros) apresentassem quatro características: (i) características físicas similares; (ii) destinação final do produto similar; (iii) tratamento similar pelos consumidores dado ao produto para alcançar a satisfação de uma demanda; e (iv) a classificação internacional dos produtos para definição do imposto de importação (Nomenclatura Comum de Mercadorias - NCM):

7.235 Para demonstrar que os produtos mexicanos de atum e produtos de atum originários dos Estados Unidos ou de qualquer outro país são semelhantes, o México seguiu a abordagem derivada do Relatório do Grupo de Trabalho do GATT sobre Ajustes Fiscais Fronteiriços. Essa abordagem baseia-se numa análise de quatro critérios gerais, que refletem quatro categorias de características que os produtos envolvidos podem compartilhar: (i) as propriedades físicas dos produtos, (ii) a medida em que os produtos são capazes de servir o mesmo ou outros fins, (iii) a medida em que os consumidores percebem e tratam os produtos como meios alternativos para desempenhar funções específicas para satisfazer uma necessidade ou demanda específica e (iv) a classificação internacional dos produtos para tarifas (WTO, 2019b, p. 171).

Diante desses itens, entendeu-se que o atum mexicano, o atum americano e o atum de outros países membros da OMC eram, de fato, similares. Contudo, não obstante a similaridade, o painel concluiu que não foram apresentadas provas suficientes de que a norma estadunidense estaria violando o art. 2.1 do TBT, já que, para o painel, a medida estadunidense seria neutra, impondo disposições gerais para qualquer atum. Apenas coincidentemente, as circunstâncias teriam gerado um impacto negativo às importações de atum mexicano, concluiu o painel.

Apesar de reconhecer que os produtos que contam com o selo de proteção aos golfinhos tinham um valor de mercado distinto - conclusão 
exarada da análise do fato de que seus destinatários no mercado estadunidense, ou seja, os consumidores daquele país tendem a rejeitar o atum que não apresenta o selo de proteção aos golfinhos, caracterizando, assim, um maior benefício ao atum estadunidense e demais que portassem o selo - o Grupo Especial posicionou-se no sentido que tais fatores não alteravam as condições justas de competição, já que a rejeição americana seria fruto da conscientização de proteção aos golfinhos e dos movimentos ambientais das décadas de 1980 e 1990 :

7.287 Concordamos com os Estados Unidos que as decisões dos consumidores dos Estados Unidos em querer comprar produtos de atum com a proteção aos golfinhos são o resultado de suas próprias escolhas e não das medidas. No entanto, como observado acima, são as próprias medidas que controlam o acesso ao rótulo e permitem que os consumidores expressem suas preferências pelo atum certificado. Por conseguinte, é proporcionada uma vantagem aos produtos elegíveis para o rótulo, pelo acesso a tal rótulo.

7.288 Observamos ainda que é incontestável que os consumidores dos Estados Unidos são sensíveis à questão dos golfinhos. Isto é reconhecido tanto pelo México quanto pelos Estados Unidos, e também é confirmado pela evidência apresentada com o amicus curiae brief a que os Estados Unidos se referiram em suas respostas a perguntas. Essa evidência sugere que, após a campanha pública da organização ambiental Earth Island Institute no final da década de 1980 (inclusive através de imagens filmadas em 1987-88 mostrando a captura e matança de golfinhos durante uma viagem de pesca onde se utilizou golfinhos) os processadores de atum estavam sob pressão para parar de comprar atum capturado em condições prejudiciais aos golfinhos. A evidência apresentada ao Painel também mostra que os principais processadores de atum reagiram a essas preocupações com os golfinhos e que isso levou a mudanças em suas políticas de compras a partir de abril de 1990. Essas políticas ainda estão em vigor: essas empresas não comprarão atum de embarcações de peixe em associação com golfinhos (WTO 2019b, p. 181).

Portanto, a OMC reconhecia que os consumidores dos Estados Unidos eram sensíveis à questão dos golfinhos e que os principais processadores de atum tinham reagido às campanhas de sensibilização sobre as preocupações relacionadas com a pesca de Atum associada aos golfinhos, gerando mudanças nas políticas de compra.

7.289 Esses elementos sugerem que o rótulo seguro para os golfinhos tem um valor comercial significativo no mercado norte-americano de produtos de atum, como o único meio pelo qual o status de golfinho pode ser reivindicado. De fato, a evidência de que se recuse a comprar atum capturado em associação aos golfinhos sugere que a pressão é suficiente para induzir os processadores de produtos de atum a evitar completamente o atum que tornaria seus produtos finais inelegíveis para 
o rótulo. Embora esta seja apenas evidência indireta quanto aos comportamentos dos consumidores finais, sugere que os próprios produtores assumem que não poderiam vender produtos de atum que não atendessem aos requisitos de proteção aos golfinhos, ou pelo menos não a um preço suficiente para garantir sua compra (WTO 2019b, p. 181).

Além de entender que a rejeição do mercado se pautava nas escolhas dos consumidores, o painel fundamentou-se, principalmente, no fato de que a medida estadunidense buscou impor restrições à prática de pesca Setting On Dolphins, não no país mexicano ou nos produtos de sua origem - que, apenas por coincidência, se utiliza dessa técnica. Ainda, constatou-se que a norma americana não teria tornado impossível a adequação do atum mexicano ao selo, apenas previa limitações à técnica de pesca que estava sendo utilizada e poderia ser substituída.

7.377 No caso em apreço parece-nos que as medidas em causa, ao aplicar o mesmo requisito de origem neutra a todos os produtos de atum, não discriminam de forma intrínseca com base na origem dos produtos e que também não é impossível que o atum mexicano cumpra esse requisito.

7.378 Em vez disso, com base nos elementos que nos são apresentados neste processo, parece-nos que o impacto das disposições dos Estados Unidos sobre golfinhos em diferentes operadores no mercado e sobre produtos de atum de várias origens depende de uma série de fatores que não são relacionado à nacionalidade do produto, mas às práticas de pesca e compras, localização geográfica, integração relativa de diferentes segmentos de produção e opções econômicas e de marketing. Neste contexto, o impacto adverso particular dos produtos de atum mexicanos no mercado dos Estados Unidos é, em nossa opinião, principalmente o resultado de "fatores ou circunstâncias não relacionadas à origem estrangeira do produto", incluindo as escolhas feitas pela própria frota de pesca do México e conservas (WTO, 2019b, p. 206).

Mediante a análise das circunstâncias apontadas, o Grupo Especial entendeu pela ausência de inconsistência da medida estadunidense em relação ao disposto no artigo 2.1 do Acordo de Barreiras Técnicas. De outro norte, sobre a não imposição de obstáculos desnecessários ao comércio, o Grupo Especial entendeu que o regulamento técnico americano estava, de fato, violando o art. 2.2 do Acordo de Barreiras Técnicas.

Para tal decisão, analisou-se se o regulamento técnico alcançava um objetivo legítimo e se a barreira estabelecida não seria mais restritiva que o necessário para atingir o objetivo pretendido, levando-se em conta o risco que o não preenchimento do requisito criaria (WTO, 2019b, p. 207).

Os objetivos legítimos apontados pelos Estados Unidos e citados 
no relatório do Grupo Especial foram: (i) garantir que os consumidores tivessem clareza sobre o produto que estariam adquirindo, sendo informados sobre o respeito à proteção dos golfinhos quando da pesca do atum; (ii) contribuir para a proteção dos golfinhos por meio da garantia de que o Estado Americano não encoraja a pesca de atum sem o devido cuidado aos golfinhos (WTO, 2019b, p. 210).

Sobre a barreira técnica não ser mais restritiva que o necessário, o país americano asseverou (e o relatório do Grupo Especial acompanhou) que a questão deveria ser analisada sob a ótica de não existir outra forma de alcançar os objetivos supradescritos que fosse significantemente menos gravosa (WTO, 2019b, p. 219-220).

Entretanto, para o México, uma forma menos gravosa e mais razoável seria permitir o uso do selo Dolphin Safe disciplinado no Acordo Internacional da Conservação dos Golfinhos. O México alegou que o objetivo estaria sendo alcançado, pois os consumidores estavam sendo informados sobre a segurança dos golfinhos, de uma forma menos prejudicial, menos gravosa, conforme relatos do Grupo Especial (WTO, 2019b, p. 251).

Com base nas alegações supraexpostas, o Grupo Especial concluiu que a norma estadunidense trazia uma restrição além do necessário (embora trouxesse proteção aos golfinhos), já que as determinações do acordo internacional para o uso do selo eram eficientes e também alcançavam os objetivos de proteção aos golfinhos. No mais, sobre a pretensão estadunidense em restringir o uso da técnica Setting On Dolphins, entendeu-se mais restritiva que o necessário mediante a ausência de prova dos efeitos gerados nos golfinhos e na diferença desses efeitos quando utilizada a mesma técnica fora do ETP (WTO, 2019b, p. 262-263).

O último ponto analisado pelo Grupo Especial pautou-se na observância do princípio da harmonização, disposto no artigo 2.4 do Acordo de Barreiras Técnicas. Enquanto o México afirmava que as medidas americanas para a certificação do Dolphin Safe não se baseavam no padrão internacional relevante existente (acordo AIDCP), os Estados Unidos defendiam o fato de que o $A I D C P$ não estabelecia um padrão relevante. No mais, afirmava que as definições de segurança ao golfinho do acordo mencionado não alcançam os objetivos americanos, como relatou o Grupo Especial (WTO, 2019b, p. 263).

Para dirimir tal questão, o Grupo Especial relatou acerca dos objetivos do AIDCP: 
1. Para reduzir progressivamente a mortalidade incidental de golfinhos na pesca de atum na área de contrato até níveis que se aproximam de zero, através da fixação de limites anuais;

2. Com o objetivo de eliminar a mortalidade de golfinhos nesta pescaria, buscar meios ecologicamente saudáveis para capturar grandes atuns que não estejam associados a golfinhos; e,

3. Para assegurar a sustentabilidade a longo prazo das unidades populacionais de atum na área em questão, bem como a dos recursos marinhos relacionados a esta pescaria, levando em consideração a inter-relação entre as espécies no ecossistema, com ênfase especial, entre outras coisas, em evitar, reduzir e minimizar as capturas acessórias e descartes de atuns juvenis e espécies não visadas (WTO, 2019b, p. 278).

Independentemente dos objetivos legítimos do AIDCP, o Grupo Especial concluiu que tais previsões não atingiriam completamente $o$ intuito estadunidense de informar aos consumidores de que não haviam sido provocados quaisquer efeitos negativos aos golfinhos durante a pesca do atum, haja vista que o selo do acordo internacional apenas almejava eliminar a morte dos mamíferos (WTO, 2019c, p. 289). Assim sendo, para o Grupo Especial, os Estados Unidos não agiam de forma inconsistente com o artigo 2.4 do Acordo de Barreiras Técnicas. Diante de todos os pontos analisados, o Grupo Especial, na conclusão de seu relatório, recomendou a seguinte decisão:

\section{DECISÕES E RECOMENDAÇÕES}

8.1 À luz das conclusões acima referidas, o Painel conclui que as disposições dos Estados Unidos sobre golfinhos:

(A) não são incompatíveis com o Artigo 2.1 do Acordo ABTC;

(B) são incompatíveis com o artigo 2.2 do Acordo ABTC porque são mais restritivos para o comércio do que o necessário para atingir um objetivo legítimo, levando em consideração os riscos que a falta de cumprimento criaria;

(C) não são incompatíveis com o Artigo 2.4 do Acordo ABTC (WTO, 2019b, p. 292).

O Órgão de Apelação, contudo, não acolheu esses posicionamentos na íntegra, e em seu relatório assim decidiu:

\section{Conclusões}

Pelas razões expostas no presente relatório, o Órgão de Apelação:

(A) constata que o Painel não cometeu erros ao caracterizar a medida em questão como Regulamento Técnico na acepção do Anexo 1.1 do Acordo ABTC;

(B) constata que o Painel cometeu um erro na interpretação e aplicação da frase “tratamento não menos favorável" no Artigo 2.1 do Acordo ABTC; Inverte a conclusão do Painel, nos parágrafos 7.374 e 8.1 (a), de que as disposições de rotulagem dolphin safe dos Estados Unidos não são incompatíveis com o Artigo 2.1 do Acordo ABTC; e considera, em vez disso, que as disposições de rotulagem dolphin safe dos Estados 
Unidos são incompatíveis com o Artigo 2.1 do Acordo ABTC;

(C) constata que o Painel cometeu um erro ao concluir, nos parágrafos 7.620 e 8.1

(b), que demonstrou que a medida em questão é mais restritiva do que o necessário para cumprir os objetivos legítimos dos Estados Unidos, tomando conta dos riscos que a falta de cumprimento criaria; E, por conseguinte, inverte a conclusão do Painel de que a medida em causa é incompatível com o Artigo 2.2 do Acordo ABTC (WTO, 2019c, p. 151-152).

Com relação às alegações do México, o Órgão de Apelação frisou:

(D) rejeita a alegação do México de que o Painel cometeu um erro ao considerar que o objetivo dos Estados Unidos de "contribuir para a proteção dos golfinhos, assegurando que o mercado dos Estados Unidos não seja usado para encorajar as frotas de pesca a capturar atum de forma prejudicial aos golfinhos" seja um objetivo legítimo na acepção do artigo 2.2 do Acordo ABTC;

(E) rejeita o pedido do México em considerar a medida em causa incompatível com o Artigo 2.2 do Acordo ABTC com base na conclusão do Painel de que a medida não cumpriu inteiramente seus objetivos (WTO, 2019c, p. 151-152).

Finalmente, quanto ao fato de a certificação Dolphin Safe do AIDCP constituir um padrão internacional e ser incompatível com o Acordo ABTC:

(F) inverte a constatação do Painel, no parágrafo 7.707, de que a definição e certificação Dolphin Safe do AIDCP constitui um padrão internacional relevante na acepção do Artigo 2.4 do Acordo ABTC. À luz desta conclusão, a conclusão do painel, no parágrafo 8.1 (c), de que a medida em questão não é incompatível com o Artigo 2.4 do Acordo ABTC, se mantém; e

(G) constata que o Painel agiu de forma incompatível com o artigo 11 do ESD ao decidir exercer a judicial economy em relação aos pedidos do México nos termos dos artigos I:1 e III:4 do GATT de 1994 (WTO, 2019c, p. 151-152).

Assim como para o Grupo Especial, para o Órgão de Apelação a regra estadunidense constituiu um regulamento técnico. (WTO, 2019c, p. 80). Contudo, sobre a interpretação do tratamento menos favorável do artigo 2.1 do TBT, o Órgão de Apelação entendeu que a norma americana é incompatível, porquanto restringe o acesso do atum mexicano, alterando as condições de concorrência no mercado estadunidense, concedendo ao México tratamento menos favorável em comparação aos produtos mexicanos e originais de outros países membros. Ainda, teria discriminado a pesca de atum no ETP e nas demais áreas ao redor do mundo, conforme segue:

À luz de fatos e constatações factuais incontestáveis feitas pelo Painel, consideramos que o México estabeleceu a prova prima facie que as disposições de rotulagem dolphin safe modificam as condições de concorrência no mercado dos Estados 
Unidos em detrimento dos produtos mexicanos de atum e não são igualitárias na forma como abordam os riscos para os golfinhos decorrentes de diferentes técnicas de pesca em diferentes áreas do oceano.

[...] Assim, em nossa opinião, os Estados Unidos não justificaram como não sendo discriminatórios os diferentes requisitos que aplicam ao atum capturado pela criação de golfinhos dentro da ETP e do atum capturado por outros métodos de pesca fora do ETP para acesso ao rótulo Dolphin Safe dos Estados Unidos, nos termos do artigo 2.1. Os Estados Unidos, portanto, não demonstrou que o impacto prejudicial da sua medida sobre os produtos de atum mexicanos decorre exclusivamente de uma distinção reguladora legítima.

Por estas razões, invocamos a conclusão do Painel, nos parágrafos 7.374 e 8.1 (a), de que as disposições de rotulagem Dolphin Safe dos Estados Unidos não são incompatíveis com o Artigo 2.1 do Acordo ABTC. Achamos, em vez disso, que as disposições de rotulagem Dolphin Safe fornecem "tratamento menos favorável" aos produtos de atum mexicanos do que o concedido aos produtos de atum dos Estados Unidos e aos produtos de atum originários de outros países e, portanto, são incompatíveis com o Artigo 2.1 da O Acordo ABTC (WTO, 2019c, p. 114-115).

Novamente em contramão ao entendimento do painel, o Órgão de Apelação analisou o artigo 2.2 do Acordo de Barreiras Técnicas. Para o Órgão de Apelação, a norma americana não é mais restritiva que o necessário, pois visa informar o consumidor sobre quaisquer prejuízos sofridos pelos golfinhos. e não apenas sobre a mortalidade destes (o que é protegido pelo acordo internacional). Assim sendo, entendeu-se que o objetivo dos Estados Unidos não seria atingido da mesma maneira apenas com as limitações do AIDCP (WTO, 2019c, p. 127).

Por fim, sobre a análise do 2.4 do Acordo de Barreiras Técnicas, novamente houve reforma da decisão do painel. Para o Órgão de Apelação, entre outras razões, o AIDCP não constitui padrão internacional relevante, pois, para ser internacional, não se faz necessário apenas que o acordo seja aberto (livre participação), mas também que todas as etapas de desenvolvimento dos standards sejam abertas. Importante destacar que tal interpretação foi dada pelo comitê do Acordo de Barreiras Técnicas (WTO, 2019a, p. 142). Assim sendo, não há que se falar em inconsistência com padrão internacional, mantendo, dessa forma, a decisão quanto à não inconsistência da medida.

Diante da decisão acolhida pelos membros, determinou-se que os Estados Unidos tornassem seu regulamento técnico compatível com as disposições do Acordo de Barreiras Técnicas. Ocorre que o México ainda busca tal adequação, tendo solicitado um Compliance Panel em 2015 e autorização para retaliar o país americano em 2016. 


\section{CONCLUSÃO}

O direito internacional ambiental, típico processo da globalização jurídica, resultou dos excessos da sociedade de consumo. Assim, a legislação protetiva do meio ambiente de direito animal, criada por volta das décadas de 1960 e 1970, trouxe um processo multifacetado e que se envolveu com o emaranhado jurídico do direito do comércio internacional. Diferente não se passou com a rotulagem Dolphin Safe. A tensa conexão entre os interesses da indústria de atum e medidas que viabilizassem proteção aos golfinhos, acompanhada por Organizações Não Governamentais (ONGs) ambientais e Organizações de Consumidores, fez desse assunto um dos mais complexos na OMC.

Depois de as grandes processadoras de atum sucumbirem às pressões das ONGs e se alinharem em prol da certificação Dolphin Safe, era a vez de o atum mexicano ser alcançado pelo marco do direito ambiental. Enquanto a indústria atuneira dos Estados Unidos fazia esforços para diminuir a vantagem competitiva do país vizinho, o México procurava soluções para superar os ditames normativos ambientais. Sob tal signo, as decisões da OMC findaram por eleger mudança de equilíbrio entre os envolvidos, maxime no caso denominado Tuna II.

Com a reforma da decisão por parte do Órgão de Apelação do Sistema de Solução de Controvérsias da Organização Mundial do Comércio, a única inconsistência encontrada na medida estadunidense foi o tratamento menos favorável aplicado ao atum mexicano em comparação ao atum estadunidense e ao atum dos demais países membros. Assim, por meio da decisão final sob a diretriz da adequação às normas da $\mathrm{OMC}$ sobre barreiras técnicas não tarifárias e sob a ótica das condições justas de concorrência no comércio internacional, tem-se que, de fato, julgou coerentemente o Órgão de Apelação.

Por mais que as restrições americanas não dissessem respeito diretamente às barreiras técnicas no processo de importação, podendo o México exportar para os Estados Unidos atum sem o selo Dolphin Safe, tem-se que tal restrição trouxe um tratamento diferenciado e desfavorável ao país mexicano, pois, ao restringir o uso do selo com normas desproporcionais e discriminatórias (pesca na área ETP), restringiu-se o acesso do atum mexicano ao mercado americano, alterando as condições de concorrência.

Isso porque é de conhecimento da comunidade, conforme 
supraexposto, que o atum que não se utiliza do selo de proteção aos golfinhos sofre grande rejeição por parte do consumidor estadunidense. Conclui-se pela concordância da decisão que se pautou na preocupação econômica dos reflexos da medida que se utilizou da certificação para, na verdade, impor uma medida protecionista da indústria nacional americana, trazendo concorrência desleal.

Com isso, a OMC estabeleceu uma nova balança de poder entre clamores ambientais, direito animal, normas comerciais e interesses nacionais, já que se revelou impossível ofertar alternativa que satisfizesse concomitantemente os interesses da indústria atuneira estadunidense da indústria atuneira mexicana, das ONGs e, por que não dizer, dos próprios animais que figuravam como sujeitos não legitimados para ofertarem suas razões. Sob tal realidade, os fundamentos das decisões da OMC refletem o estado da arte quando a discussão diz respeito à acomodação do direito do comércio internacional diante das exigências da preservação animal.

\section{REFERÊNCIAS}

IATTC - INTER-AMERICAN TROPICAL TUNA COMMISSION. Agreement on the International Dolphin Conservation Program (AIDCP). La Jolla: IATTC, 2005. Disponível em: <https://www.iattc.org/PDFFiles2/ AIDCP-Dolphin-Safe-certification-system-REV-Oct2005.pdf $>$. Acesso em: 11 abr. 2019.

NETO, O. C. S. Liberação do comércio e outros valores. In: BARRAL, W.; PIMENTEL, P. (Coords.). Comércio internacional e desenvolvimento. Florianópolis: Fundação Boiteux. 2006. p. 87-113.

OLIVEIRA, S. M. Barreiras não tarifárias no comércio internacional e direito ao desenvolvimento. Rio de Janeiro: Renovar, 2005.

SYKES, A. O. Regulatory consistency requirements in international trade. Stanford Law and Economics Olin Working Paper, n. 502, 18 jan. 2017. Disponível em: $<$ https://ssrn.com/abstract=2901653>. Acesso em: 12 nov. 2017.

WTO - WORLD TRADE ORGANIZATION) Agreement on technical barriers to trade. Disponível em: <http:/www.worldtradelaw.net/ uragreements/tbtagreement.pdf.download\#page $=1>$. Acesso em: 15 abr. 2019a. 
. United States - Measures Concerning the Importation, Marketing and Sale of Tuna and Tuna Products - US TUNA II (Relatório do Grupo Especial 381 de 2013). Disponível em: <https://www.wto.org/english/ tratop_e/dispu_e/cases_e/ds381_e.htm\#collapseA>. Acesso em: 10 abr. $2019 b$.

. United States - Measures Concerning the Importation, Marketing and Sale of Tuna and Tuna Products - US TUNA II (Relatório do órgão de apelação 381 de 2015). Disponível em: <https://www.wto.org/english/ tratop_e/dispu_e/cases_e/ds381_e.htm\#collapseA>. Acesso em: 11 abr. 2019c.

. United States - Measures Concerning the Importation, Marketing and Sale of Tuna and Tuna Products - US TUNA I (Relatório do órgão especial DS21/R de 1991). Disponível em: <https://www.wto.org/english/ tratop_e/dispu_e/gatt_e/91tuna.pdf $>$. Acesso em: 24 abr. 2019d.

Artigo recebido em: 05/05/2019.

Artigo aceito em: 13/06/2019.

\section{Como citar este artigo (ABNT):}

STELZER, J.; GONÇALVES, E. N.; WIEIRA, K. A compreensão da OMC sobre a certificação 'Dolphin Safe' na pesca do atum: o caso US Tuna II. Veredas do Direito, Belo Horizonte, v. 16, n. 35, p. 245-268, maio/ ago. 2019. Disponível em: <http://www.domhelder.edu.br/revista/index. $\mathrm{php} / \mathrm{veredas} /$ article/view/1535>. Acesso em: dia mês. ano. 